\title{
PRODUKTIVITAS TENAGA KERJA, TITIK IMPAS NILAI PENJUALAN DAN HARGA POKOK PRODUKSI AGROINDUSTRI TEPUNG AREN
}

\section{LABOR PRODUTIVITY, BREAK EVEN POINT SALES VALUE AND COST OF GOODS MANUFACTURED IN PALM FLOUR AGROINDUSTRY}

\author{
Suyudi*, Nurul Risti Mutiarasari, Zulfikar Noormansyah \\ Fakultas Pertanian, Universitas Siliwangi, Tasikmalaya \\ *E-mail: suyudi@unsil.ac.id \\ (Diterima 01-04-2021; Disetujui 03-06-2021)
}

\begin{abstract}
ABSTRAK
Tepung aren merupakan hasil dari proses produksi pengolahan dari batang pohon aren. Penelitian ini bertujuan untuk mengetahui produktivitas tenaga kerja, titik impas nilai penjualan, titik impas volume produksi, dan Harga Pokok Produksi (HPP). Metode penelitian yang digunakan adalah studi kasus pada Agroindustri Tepung Aren PT. AKS Gunung Wangi di Desa Kertaharja, Kecamatan Cijeungjing, Kabupaten Ciamis. Alat analisis kuantitatif yang digunakan dalam penelitian ini adalah produktivitas tenaga kerja, titik impas dari nilai penjualan dan volume produksi, serta harga pokok produksi. Pengukuran produktivitas tenaga kerja untuk mengetahui kondisi ekonomi tenaga kerja dari suatu usaha yang dilakukan, selanjutnya analisis titik impas berguna untuk mengetahui kaitan antara nilai penjualan dan volume produksi dengan harga dan biaya lainnya, sedangkan penentuan harga pokok produksi bertujuan untuk menghitung besarnya biaya atas pemakaian sumber ekonomi dalam proses produksi. Hasil penelitian menunjukkan bahwa produktivitas tenaga kerja pada agroindustri tepung aren PT AKS Gunung Wangi sebesar Rp 351.562,50 /Hari Kerja Orang untuk satu kali proses produksi. Proses pengolahan tepung aren dalam satu kali proses produksi memerlukan waktu selama 4 hari. Titik impas dari nilai penjualan sebesar Rp 604.118,76 dan volume produksi 80,55 kilogram dengan kapasitas produksi sebanyak 1.200 kilogram. Harga pokok produksi pada Agroindustri Tepung Aren sebesar Rp 5.167,65 per kilogram.
\end{abstract}

Kata kunci: produksi, produktivitas, tenaga kerja, tepung aren, titik impas

\begin{abstract}
Palm flour is the result of the processing production from the palm tree trunk. This study aims to determine labor productivity, the breakeven point of sales value, the breakeven point of production volume, and the cost of goods manufactured. The research method used is a case study at PT. AKS Gunung Wangi in Kertaharja Village, Cijeungjing District, Ciamis. Quantitative analysis tools used in this research are labor productivity, the break-even point of the sales value and production volume, and the cost of goods manufactured. Labor productivity is measured to determine the economic condition of the labor force of a business carried out, then the break-even point analysis is useful for knowing the relationship between sales value and production volume with prices and other costs, while determining the cost of goods manufactured aims to calculate the cost of using resources. economy in the production process. The results showed that the labor productivity in PT AKS Gunung Wangi's palm flour agroindustry was Rp. 351,562,50 / person working day for one production process. Processing of palm flour in one production process takes 4 days. The breakeven point of the sales value is Rp. 604,118.76 and a production volume of 80.55 kilograms with a production capacity of 1,200 kilograms. The cost of production in the Palm Flour Agroindustry is Rp. 5,167.65 per kilogram.
\end{abstract}

Keywords: break even point, labor, palm flour, production, productivity 


\section{PRODUKTIVITAS TENAGA KERJA, TITIK IMPAS NILAI PENJUALAN \\ DAN HARGA POKOK PRODUKSI AGROINDUSTRI TEPUNG AREN \\ Suyudi, Nurul Risti Mutiarasari, Zulfikar Noormasyah}

\section{PENDAHULUAN}

Pembangunan ekonomi akan masih tetap berbasis pertanian secara luas, terlebih masa yang akan datang posisi pertanian merupakan sektor andalan dalam pembangunan sehingga peranan agroindustri akan semakin besar, mengingat eratnya keterkaitan antara sektor pertanian dan sektor industri maka dalam pembangunan ekonomi yang berorientasi pada agroindustri merupakan strategi industrialisasi yang tepat (Daryanto, 2009). Hal tersebut dikarenakan sebagian besar sumber daya berada di sektor pertanian dan sebagian besar penduduk masih bergantung pada sektor pertanian. Salah satu agroindustri yang saat ini banyak berkembang, khususnya di Kabupaten Ciamis adalah agroindustri tepung aren. Agroindustri tepung aren di Kabupaten Ciamis tersebar di beberapa kecamatan, yaitu Kecamatan Panawangan dan Kecamatan Cijeungjing. Desa Kertaharja, Kecamatan Cijeungjing merupakan sentra industri pengolahan tepung aren di Kabupaten Ciamis (Dinas Koperasi, UKM dan Perdagangan Kabupaten Ciamis, 2019).

Dalam menjalankan sebuah organisasi, industri maupun perusahaan, diperlukan sumber daya manusia yang menjadi salah satu asset utama sebagai perencana dan pelaku aktif dari setiap aktivitas organisasi. Kualitas dan kuantitas sumber daya manusia disesuaikan dengan kebutuhan organisasi supaya efektif dan efisien menunjang tercapainya tujuan organisasi (Hasibuan, 2012). Kualitas sumber daya manusia dapat diukur melalui produktivitas kerjanya. Produktivitas kerja karyawan menurut Gaol (2014) adalah perilaku nyata yang ditampilkan setiap orang sebagai prestasi kerja yang dihasilkan oleh karyawan sesuai dengan perannya di lembaga atau perusahaan. Setiap perusahaan selalu mengharapkan karyawannya mempunyai produktivitas kerja yang tinggi, karena dengan memiliki karyawan yang berproduktivitas kerja tinggi akan memberikan sumbangan yang optimal bagi perusahaan. Selain itu, dengan memiliki karyawan yang berproduktivitas kerja tinggi perusahaan dapat meningkatkan produktivitas kerjanya.

PT. AKS Gunung Wangi merupakan agroindustri yang bergerak di bidang usaha pengolahan tepung aren yang menggunakan sumber daya manusia sebagai karyawan dan berorientasi komersial. Oleh sebab itu, dalam menjalankan perusahaan, PT.AKS 
Gunung Wangi harus memperhatikan produktivitas tenaga kerja dan melakukan perhitungan harga pokok produksi secara tepat, sehingga dapat digunakan sebagai sarana pengendalian biaya produksi, serta sebagai dasar bagi penentuan harga jual produknya, agar harga jual dari produk yang dihasilkan dapat bersaing dengan produk sejenis di pasaran. Mulyadi (2015) menyatakan bahwa dalam melakukan proses produksinya perlu diketahui juga mengenai titik impasnya, sehingga perusahaan memiliki patokan atau acuan dalam proses produksinya. Titik impas adalah sebuah titik dimana biaya atau pengeluaran dan pendapatan adalah seimbang sehingga tidak mengalami kerugian maupun keuntungan.

Berdasarkan latar belakang di atas, maka penulis tertarik untuk mengadakan penelitian mengenai "Produktivitas tenaga kerja, Titik Impas dan Harga Pokok Produksi pada Agroindustri Tepung Aren" studi kasus pada agroindustri tepung aren PT. AKS Gunung Wangi.

\section{METODE PENELITIAN}

Metode yang digunakan dalam penelitian ini adalah metode studi kasus pada agroindustri PT. AKS Gunung
Wangi di Desa Kertaharja Kecamatan Cijeungjing Kabupaten Ciamis. Lokasi penelitian ini dipilih secara sengaja (purposive), dengan pertimbangan bahwa Kecamatan Cijeungjing merupakan sentra agroindustri tepung aren di Kabupaten Ciamis, dan Desa Kertaharja menghasilkan industri terbanyak di Kecamatan Cijeungjing. Penelitian studi kasus merupakan suatu penelitian yang dilakukan secara intensif terinci dan mendalam terhadap suatu lembaga atau gejala tertentu (Arikunto, 2006).

Produktivitas tenaga kerja bertujuan untuk mengetahui kondisi ekonomi tenaga kerja dari suatu usaha yang dilakukan. Secara umum yang dimaksud dengan produktivitas kerja adalah perbandingan antara hasil yang dicapai (output) dengan keseluruhan sumber daya yang digunakan (input). Berikut rumus dalam mengukur produktivtas tenaga kerja:

Produktivitas Tenaga Kerja = Total Penerimaan

$\overline{\text { Jumlah tenaga harian pada setiap proses produksi }}$

Penerimaan menurut Suratiyah (2015) adalah seluruh pendapatan yang diperoleh dari usahatani selama satu periode diperhitungkan dari hasil penjualan atau penaksiran kembali, dengan rumus sebagai berikut: 
$T R=\operatorname{Py} x Y$

Keterangan:

$\mathrm{TR}=$ Total Revenue/Penerimaan

Py $\quad=$ Harga Produk $(\mathrm{Rp} / \mathrm{Kg})$

$\mathrm{Y} \quad=$ Jumlah Produksi $(\mathrm{Kg})$

Pendapatan adalah selisih dari pendapatan kotor dengan biaya mengusahakan, dengan rumus sebagai berikut:

$\Pi=T R-T C$

Keterangan:

$\Pi=$ Pendapatan

TR = Total Revenue/Penerimaan

$\mathrm{TC}=$ Total Cost/Biaya Total

Analisa break even menurut Sigit (1990) adalah suatu cara atau teknik untuk mengetahui kaitan antara volume produksi, volume penjualan, harga jual, biaya produksi, biaya lainnya yang variabel dan yang tetap, serta laba dan rugi. Analisa break even adalah suatu cara atau suatu teknik yang digunakan oleh seorang petugas/manager perusahaan untuk mengetahui pada volume (jumlah) penjualan dan volume produksi berapakah perusahaan yang bersangkutan tidak menderita kerugian dan tidak pula memperoleh laba, dengan rumus sebagai berikut:

$B E P$ Nilai Penjualan $=\frac{F C}{1-V C / S}$
Keterangan:

FC = Fixed Cost/Biaya Tetap

$\mathrm{VC}=$ Variable Cost/Biaya Variabel

$\mathrm{S} \quad=$ Selling/Penjualan

BEP Volume Produksi $=\frac{\text { BEP Nilai Penjualan }}{\text { Harga Jual }}$

Adikoesoema (1986) berpendapat bahwa perhitungan harga pokok adalah menghitung besarnya biaya atas pemakaian sumber ekonomi dalam memproduksi barang atau jasa, dengan rumus sebagai berikut:

$H P P=\frac{T C}{Q}$

Keterangan :

HPP = Harga Pokok Produksi

$\mathrm{TC}=$ Total Cost $/$ Biaya Total (Rp)

$\mathrm{Q} \quad=$ Jumlah produk yang dihasilkan $(\mathrm{Kg})$

\section{HASIL DAN PEMBAHASAN}

\section{Identitas Responden}

Responden pada penelitian ini adalah H. Ateng Kadar Saleh, berumur 60 tahun, pendiri agroindustri tepung aren PT. AKS Gunung Wangi. Pendidikan terakhir yang ditempuh responden adalah Sekolah Dasar (SD). Kondisi ekonomi yang dialami menyebabkan responden tidak dapat melanjutkan pendidikan. Dalam 
menjalankan usaha agroindustri tepung aren, responden memiliki pengalaman selama 20 tahun.

\section{Gambaran Usaha PT. AKS Gunung Wangi}

Agroindustri PT. AKS Gunung Wangi adalah usaha agroindustri tepung aren yang didirikan oleh $\mathrm{H}$. Ateng Kadar Saleh pada tahun 2000 yang berlokasi di Desa Kertaharja, Kecamatan Cijeungjing, Kabupaten Ciamis. Responden sebelumnya pernah bekerja sebagai buruh tani, tetapi penghasilan yang diperoleh tidak dapat memenuhi kebutuhannya yang membuat responden ingin mencari penghasilan tambahan agar dapat mencukupi semua kebutuhannya. Seiring berjalannya waktu, responden mempunyai ide untuk mengolah batang pohon aren menjadi tepung aren karena melihat peluang pohon aren yang ada disekitarnya. Responden mempunyai modal awal sebesar Rp 500.000,00 dari hasil buruh tani dengan hasil produksi awal sebanyak $\pm 1,5-2$ Kwintal karena belum menggunakan mesin sama sekali. Seiring waktu dan banyaknya permintaan, saat ini usaha agroindustri tepung aren milik responden mampu memproduksi $\pm 1-1,5$ ton dalam satu kali proses produksi.

\subsection{Ketenagakerjaan}

Tenaga kerja pada agroindustri tepung aren sebanyak 16 orang dengan jumlah tenaga kerja pria sebanyak 12 orang dan tenaga kerja wanita sebanyak 4 orang. Jika dilihat dari jumlah tenaga kerja, maka agroindustri tersebut termasuk ke dalam kategori usaha industri menengah karena jumlah tenaga kerja yang terserap lebih dari sembilan orang. Karyawan bekerja hanya sampai pekerjaannya selesai dan dengan upah yang berbeda-beda sesuai pada bidangnya, mulai dari persiapan bahan baku sampai dengan produksi tepung aren.

\subsection{Permodalan}

Sumber modal yang digunakan untuk aktivitas usaha berasal dari modal sendiri dan modal pinjaman. Responden memperoleh pinjaman modal berupa uang tunai. Adapun untuk biaya produksi yang dikeluarkan berasal dari modal sendiri, tetapi pada saat responden ingin membeli peralatan, responden kekurangan modal usaha sehingga responden meminjam modal ke Bank BRI dengan suku bunga sebesar 6 persen per tahun. Apabila dilihat dari jumlah investasinya, agroindustri tepung aren tersebut termasuk ke dalam kategori 
usaha mikro, hal tersebut dikarenakan agroindustri memiliki investasi berkisar \pm Rp 300.000.000,00.

\subsection{Pengadaan Bahan Baku}

Bahan baku utama untuk agroindustri tepung aren adalah batang pohon aren. Responden memperoleh bahan baku dari Purwokerto, Cijulang, Banjarsari, Pangandaran, Karangnunggal, Pamijahan, dan lain-lain. Bahan baku tepung aren selalu tersedia, baik dari langganan maupun dari daerah lain seperti Kuningan, Cirebon, Majalengka.

\subsection{Sarana Produksi}

Terdapat sarana produksi yang dimiliki oleh agroindustri tepung aren, yaitu pabrik pengolahan tepung aren serta alat pengolahan tepung aren (kapak, mesin penggilingan, pompa air, saringan, sekop, bak pengendapan, terpal, timbangan digital dan mesin jahit karung).

\subsection{Proses Produksi Agroindustri Tepung Aren}

Dalam menghasilkan tepung aren, terdapat beberapa proses produksi yang dilakukan, antara lain:

(1) Pemotongan dan pembelahan

Pertama dalam pembuatan tepung aren dilakukan penebangan batang pohon aren terlebih dahulu, kemudian dipotongpotong sepanjang 1,25-2 meter. Pemotongan batang aren dibelah membujur 4 bagian yang sama besar. Pembelahan batang aren dilakukan untuk mempermudah proses penggilingan. Kegiatan pembelahan dilakukan secara manual oleh manusia dengan menggunakan kapak.

(2) Penggilingan

Batang aren yang sudah dibelah dipisahkan dari kulit dalamnya, kemudian di potong-potong menjadi 6-8 bagian, lalu digiling menggunakan mesin penggiling. Hasilnya berupa serbuk, kemudian diayak untuk memisahkan serbuk-serbuk dari serat-seratnya yang kasar.

(3) Perendaman dan Pemerasan

Hasil dari penggilingan tersebut dikumpulkan, kemudian dibawa ke bak perendaman, selanjutnya dilakukan pemerasan untuk diambil patinya.

(4) Pengendapan

Serbuk atau serat yang sudah direndam dan diperas kemudian diendapkan selama \pm 12 jam. Endapanendapan tersebut menjadi pati basah, kemudian dikeringkan terlebih dahulu untuk dimanfaatkan sebagai bahan makanan.

(5) Penjemuran

Proses penjemuran dari pati basah menjadi pati kering dilakukan di tanah 
lapang dengan memanfaatkan sinar matahari dan menggunakan terpal.

(6) Pengemasan

Pengemasan dilakukan setelah pati/tepung aren sudah kering, kemudian selanjutnya dikemas menggunakan karung.

\section{Harga Jual dan Pemasaran Hasil}

Hasil penelitian menunjukkan bahwa harga tepung aren sebesar $\mathrm{Rp}$ 7.500,00 per kilogram dengan melihat besarnya harga dipasaran guna menghindari kesulitan dalam memasarkan hasil produksi tepung aren untuk bersaing dengan penjual lain yang memproduksi produk yang sama. Setiap kali proses produksi, produk tepung aren yang dihasilkan akan dijual ke pasar, ke pabrik-pabrik, ke daerah Banyuwangi, Purwokerto, Solo, dan daerah lain yang diangkut dengan menggunakan mobil truk.

\section{Analisis Biaya, Penerimaan dan Pendapatan}

\subsection{Biaya Tetap}

Biaya tetap merupakan biaya yang besar kecilnya tidak dipengaruhi oleh besar kecilnya produksi atau biaya yang tidak habis dalam satu kali proses produksi. Biaya tetap yang dikeluarkan agroindustri tepung aren dapat dilihat pada Tabel 1.

Tabel 1. Jumlah Biaya Tetap Pada

\begin{tabular}{|c|c|c|c|}
\hline \multicolumn{4}{|c|}{ Agroindustri Tepung Aren } \\
\hline No & Jenis Biaya & Nilai (Rp) & $\begin{array}{c}\text { Persentase } \\
(\%)\end{array}$ \\
\hline 1 & $\begin{array}{l}\text { Penyusutan } \\
\text { Alat }\end{array}$ & $201.053,88$ & 99,83 \\
\hline 2 & PBB & 191,80 & 0,10 \\
\hline 3 & $\begin{array}{l}\text { Bunga Modal } \\
\text { Tetap }\end{array}$ & 140,87 & 0,07 \\
\hline Tot & Biaya Tetap & $201.500,53$ & 100,00 \\
\hline
\end{tabular}

Sumber: Data Primer Diolah (2020)

Berdasarkan Tabel 1, besarnya biaya tetap yang dikeluarkan oleh responden untuk usaha agroindustri tepung aren dalam satu kali proses produksi sebesar Rp 201.386,55 yang terdiri dari penyusutan alat sebesar $\mathrm{Rp}$ 201.053,88, pajak bumi dan bangunan (PBB) sebesar Rp.191,80 dan bunga modal tetap sebesar Rp 140,87.

\subsection{Biaya Variabel}

Biaya variabel merupakan biaya yang besar kecilnya dipengaruhi oleh besar kecilnya produksi atau biaya yang habis pakai dalam satu kali proses produksi. Besarnya biaya variabel yang dikeluarkan agroindustri tepung aren dalam satu kali proses produksi sebesar Rp. 5.999.796,92, untuk lebih jelasnya dapat dilihat pada Tabel 2.

Tabel 2 menunjukkan bahwa biaya terbesar yang dikeluarkan oleh agroindustri tepung aren adalah biaya untuk pembelian bahan baku yaitu batang pohon aren sebesar Rp. 2.800.000,00 


\section{PRODUKTIVITAS TENAGA KERJA, TITIK IMPAS NILAI PENJUALAN \\ DAN HARGA POKOK PRODUKSI AGROINDUSTRI TEPUNG AREN \\ Suyudi, Nurul Risti Mutiarasari, Zulfikar Noormasyah}

(46,67 persen) dari keseluruhan biaya variabel. Solar dalam satu kali proses produksi mengeluarkan biaya sebesar Rp. 1.259.600,00 (21,00 persen) sebanyak 134 liter. Agroindustri tepung aren mempekerjakan 16 orang dengan jumlah tenaga kerja pria 12 orang dan tenaga kerja wanita 4 orang. Pembagian tenaga kerja dan upah berbeda-beda sesuai pada bidangnya dengan mengeluarkan biaya sebesar Rp. 1.542.000,00 dalam satu kali proses produksi. Plastik digunakan untuk menjual tepung aren per kilogram ke pasar dengan mengeluarkan biaya sebesar Rp. 144.000,00 (2,40 persen), kemudian karung mengeluarkan biaya sebesar Rp. 150.000,00 (2,50 persen) dengan harga satuannya sebesar Rp. 5.000,00. Listrik yang dikeluarkan untuk pabrik tepung aren sebesar Rp. $100.000,00 \quad(1,66$ persen) per satu kali proses produksi yaitu sebanyak 63,20 kwh yang digunakan untuk kabel seling pada proses pengangkutan limbah padat berupa serat dan pencahayaan di pabrik ketika malam hari. Bunga modal variabel sebesar Rp. 4.196,92 (0,07 persen) yang berasal dari bunga modal per produksi dikalikan dengan jumlah biaya variabel.

\begin{tabular}{|c|c|c|c|}
\hline 'abel & $\begin{array}{c}\text { Jumlah } \\
\text { Agroin }\end{array}$ & $\begin{array}{c}\text { Biaya } \\
\text { Istri Tepung }\end{array}$ & $\begin{array}{ll}\text { ap } & \text { Pada } \\
\text { ren } & \\
\end{array}$ \\
\hline No & Jenis Biaya & Nilai (Rp) & $\begin{array}{c}\text { Persentase } \\
(\%)\end{array}$ \\
\hline 1 & $\begin{array}{l}\text { Batang Pohon } \\
\text { Aren }\end{array}$ & $2.800 .000,00$ & 46,67 \\
\hline 2 & Solar & $1.259 .600,00$ & 21,00 \\
\hline 3 & Tenaga Kerja & $1.542 .000,00$ & 25,70 \\
\hline 4 & Plastik & $144.000,00$ & 2,40 \\
\hline 5 & Karung & $150.000,00$ & 2,50 \\
\hline 6 & Listrik & $100.000,00$ & 1,66 \\
\hline 7 & $\begin{array}{l}\text { Bunga Modal } \\
\text { Variabel }\end{array}$ & $4.196,92$ & 0,07 \\
\hline $\begin{array}{l}\text { Total } \\
\text { Varia }\end{array}$ & anel Biaya & $5.999 .796,92$ & 100,00 \\
\hline
\end{tabular}

\subsection{Biaya Total}

Biaya total merupakan keseluruhan biaya yang dikeluarkan oleh suatu perusahaan selama proses produksi berupa biaya tetap dan biaya variabel. Total biaya pada proses produksi tepung aren sebesar Rp 6.201.183,47 untuk satu kali proses produksi, dimana biaya tersebut merupakan penjumlahan antara biaya tetap sebesar Rp 201.386,55 dan biaya variabel sebesar $R p$ 5.999.796,92.

\subsection{Penerimaan dan Pendapatan}

Penerimaan yang diperoleh agroindustri tepung aren dalam satu kali proses produksi adalah hasil produksi tepung aren dikalikan dengan harga jual tepung aren yang berlaku pada saat penelitian. Hasil produksi yang diperoleh adalah 1,2 ton atau 1.200 kilogram dengan harga jual $\mathrm{Rp} 7.500,00$ per 
kilogram, sehingga diperoleh penerimaan sebesar Rp 9.000.000,00.

Pendapatan merupakan gambaran keuntungan bersih dari suatu kegiatan usaha agroindustri tepung aren. Pendapatan yang diterima oleh agroindustri tepung aren sebesar $\mathrm{Rp}$ 2.798.816,53 dimana biaya tersebut merupakan selisih antara penerimaan sebesar Rp. 9.000.000,00 dan biaya total sebesar Rp 6.201.183,47.

\section{Produktivitas Tenaga Kerja}

Dengan total penerimaan agroindustri tepung aren sebesar $\mathrm{Rp}$ 9.000.000,00 dan jumlah tenaga kerja pada setiap prosesnya adalah 25,6 HOK, diperoleh pengukuran produktivitas tenaga kerja pada agroindustri tepung aren yaitu $\mathrm{Rp} 351.562,00$. Selanjutnya hasil perhitungan produktivitas tenaga kerja, dibandingkan dengan upah harian rata-rata yang digunakan di lokasi penelitian, yaitu sebesar Rp 60.000,00. Berdasarkan hal tersebut, menunjukkan bahwa produktivitas tenaga kerja pada agroindustri tepung aren sangat tinggi. Produktivitas tenaga kerja dapat mengindikasikan pendapatan dari tenaga kerja, sehingga jika semakin tinggi tingkat produktivitas, maka akan semakin baik tingkat ekonomi tenaga kerja.

\section{Analisis Titik Impas}

Analisis titik impas merupakan analisis kelayakan usaha jangka pendek yang bertujuan untuk mengetahui titik dimana suatu usaha tidak mengalami keuntungan maupun kerugian. Seorang pemilik usaha dapat memanfaatkan analisis titik impas untuk merencanakan tingkat laba yang diinginkan pada biaya dan volume penjualan tertentu atau menargetkan volume penjualan yang mungkin dicapai pada biaya dan laba tertentu (Handono Mardiyanto, 2009).

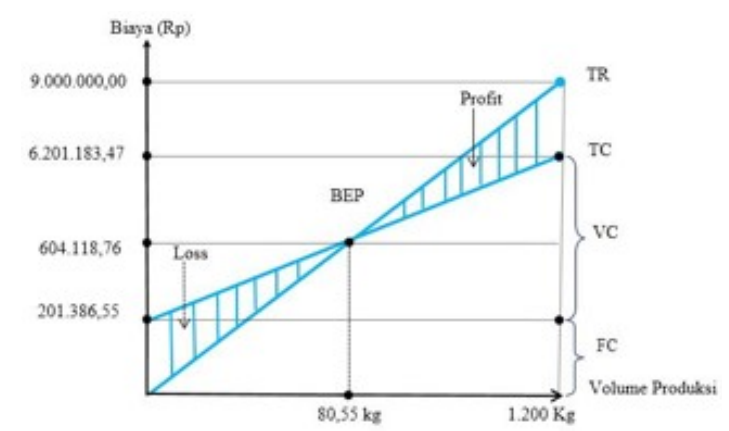

\section{Gambar 1. Analisis Titik Impas Agroindustri Tepung Aren}

Kapasitas penuh (100 persen) agroindustri tepung aren yaitu memproduksi 1.200 kilogram dengan total penerimaan sebesar $\mathrm{Rp}$ 9.000.000,00. Garis penerimaan ditarik dari titik nol ke titik Rp 9.000.000,00. Titik impas terletak pada titik perpotongan antara garis biaya total dengan garis total penerimaan. Titik impas tercapai pada nilai penjualan $\mathrm{Rp}$ 604.118,76 atau pada volume produksi 


\section{PRODUKTIVITAS TENAGA KERJA, TITIK IMPAS NILAI PENJUALAN \\ DAN HARGA POKOK PRODUKSI AGROINDUSTRI TEPUNG AREN \\ Suyudi, Nurul Risti Mutiarasari, Zulfikar Noormasyah}

80,55 kilogram. Jadi pada titik tersebut agroindustri tepung aren tidak mendapatkan keuntungan maupun kerugian. Daerah yang terletak disebelah kanan BEP merupakan daerah keuntungan, sedangkan daerah yang terletak disebelah kiri BEP merupakan daerah kerugian.

\section{Harga Pokok Produksi}

Harga pokok produksi tepung aren dalam satu kali proses produksi sebesar Rp 5.167,65 per kilogram, dimana total biaya sebesar $\operatorname{Rp} 6.201 .183,47$ dan jumlah produk tepung aren sebesar 1.200 kilogram. Jadi apabila responden menjual dibawah HPP, maka penjual akan mengalami kerugian. Berdasarkan hasil penelitian, harga jual tepung aren yaitu sebesar Rp 7.500 per kilogram, jadi responden masih mendapatkan keuntungan sebesar $\mathrm{Rp} 2.332,35$ per kilogram tepung aren.

\section{KESIMPULAN DAN SARAN}

\section{Kesimpulan}

1) Besarnya biaya total yang dikeluarkan oleh agroindustri tepung aren sebesar Rp 6.201.183,47. Penerimaan yang dihasilkan sebesar Rp 9.000.000,00 dan pendapatan sebesar $\mathrm{Rp}$
2.798.816,53 untuk satu kali proses produksi.

2) Tingkat produktivitas tenaga kerja yang dihasilkan adalah $\mathrm{Rp}$ 351.562,00, menunjukkan bahwa produktivitas tenaga kerja agroindustri tepung aren sangat tinggi.

3) Break even point (BEP) nilai penjualan sebesar $\mathrm{Rp}$ 604.118,76 dan BEP volume produksi 80,55 kilogram dengan kapasitas produksi sebanyak 1.200 kilogram. Artinya agroindustri tepung aren akan memperoleh keuntungan apabila penerimaan lebih besar dari Rp 604.118,76 dengan volume produksi lebih besar dari 80,55 kilogram.

4) Harga pokok produksi pada agroindustri tepung aren sebesar $\mathrm{Rp}$ 5.167,65 per kilogram. Artinya agroindustri tepung aren akan memperoleh keuntungan apabila penjualan tepung aren lebih besar dari Rp 5.167,65 per kilogram.

\section{Saran}

1) Perlu adanya upaya penanaman kembali pohon aren untuk keberlangsungan usaha agroindustri tepung aren.

2) Perlu adanya teknologi untuk memperlancar proses penjemuran 
tepung aren pada saat musim hujan, salah satunya dengan menggunakan alat pengering berupa oven.

3) Perlunya mengembangkan potensi yang ada dari sisa limbah penggilingan batang aren yang dapat dijual untuk tambahan penerimaan.

4) Penelitian selanjutnya diharapkan untuk meneliti mengenai manfaat dari limbah sisa penggilingan batang aren tersebut, agar tidak mencemari lingkungan yang ada di sekitarnya.

\section{DAFTAR PUSTAKA}

Arief Daryanto. 2009. Dinamika Daya Saing Industri Peternakan. IPB Press, Bogor.

Dinas Koperasi, UKM dan Perdagangan Kabupaten Ciamis. 2019. Sentra Agroindustri Tepung Aren. Ciamis.
Gaol, Jummy L. Human Capital Manajemen Sumber Daya Manusia. 2014. Penerbit PT. Gramedia Widiasarana Indonesia. Jakarta.

Hasibuan, Malayu S.P. 2012. Manajemen Sumber Daya Manusia. Edisi Revisi. Penerbit Bumi Aksara. Jakarta

Ken Suratiyah. 2015. Ilmu Usahatani Edisi Revisi. Penebar Swadaya, Jakarta. Mulyadi. 2015. Akuntansi Manajemen Edisi ketiga. Salemba Empat, Jakarta.

Suharsimi Arikunto. 2006. Prosedur Penelitian Suatu Pendekatan Praktek. Rineka Cipta, Jakarta.

Soehardi Sigit. 1990. Analisis Break Event: Ancangan Linear Secara Ringkas dan Praktis Edisi Ketiga. BPFE, Yogyakarta.

Soemita Adikoesoema. 1986. Biaya dan Harga Pokok. Tarsito, Bandung. 